\title{
Inter-laboratory quality control for hormone-dependent gene expression in human breast tumors using real-time reverse transcription-polymerase chain reaction
}

\author{
P de Cremoux ${ }^{1}$, I Bieche ${ }^{2,3}$, C Tran-Perennou $^{1}$, S Vignaud $^{4}$, E Boudou $^{1}$, \\ $B$ Asselain $^{7}, R$ Lidereau $^{2}$, H Magdelénat $^{1}, V$ Becette $^{5}, B$ Sigal-Zafrani ${ }^{6}$ \\ and $F$ Spyratos ${ }^{4}$
}

\footnotetext{
${ }^{1}$ Unité de Pharmacologie, Institut Curie, 26 rue d'Ulm, 75005 Paris, France

${ }^{2}$ Laboratoire INSERM E0017, Centre René Huguenin, Saint Cloud, France

${ }^{3}$ Laboratoire de Génétique Moléculaire, UPRES EA 3618, Faculté des Sciences Pharmaceutiques et

Biologiques de Paris, Paris, France

${ }^{4}$ Laboratoire d'Oncobiologie, Centre René Huguenin, Saint Cloud, France

${ }^{5}$ Département d'Anatomo-Pathologie, Centre René Huguenin, Saint Cloud, France

${ }^{6}$ Service d'Anatomo-Pathologie, Institut Curie, Paris, France

${ }^{7}$ Service de Biostatistiques, Institut Curie, Paris, France

(Requests for offprints should be addressed to P de Cremoux; Email: patricia.de-cremoux@curie.net)
}

\begin{abstract}
Quantitative reverse transcription-polymerase chain reaction (RT-PCR) used to detect minor changes in specific mRNA concentrations may be associated with poor reproducibility. Stringent quality control is therefore essential at each step of the protocol, including the PCR procedure.

We performed inter-laboratory quality control of quantitative PCR between two independent laboratories, using in-house RT-PCR assays on a series of hormone-related target genes in a retrospective consecutive series of 79 breast tumors. Total RNA was reverse transcribed in a single center. Calibration curves were performed for five target genes (estrogen receptor (ER) $\alpha, E R \beta$, progesterone receptor (PR), CYP19 (aromatase) and Ki 67) and for two reference genes (human acidic ribosomal phosphoprotein PO (RPLPO) and TATA box-binding protein (TBP)). Amplification efficiencies of the calibrator were determined for each run and used to calculate mRNA expression. Correlation coefficients were evaluated for each target and each reference gene.

A good correlation was observed for all target and reference genes in both centers using their own protocols and kits $(P<0.0001)$. The correlation coefficients ranged from 0.90 to 0.98 for the various target genes in the two centers. A good correlation was observed between the level of expression of the $\mathrm{ER} \alpha$ and the PR transcripts $(P<0.001)$. A weak inverse correlation was observed in both centers between $E R \alpha$ and ER $\beta$ levels, but only when TBP was the reference gene. No other correlation was observed with other parameters.

Real-time PCR assays allow convenient quantification of target mRNA transcripts and quantification of target-derived nucleic acids in clinical specimens. This study addresses the importance of interlaboratory quality controls for the use of a panel of real-time PCR assays devoted to clinical samples and protocols and to ensure their appropriate accuracy. This can also facilitate exchanges and multicenter comparison of data.
\end{abstract}

Endocrine-Related Cancer (2004) 11 489-495 


\section{Introduction}

Reverse transcription-polymerase chain reaction (RTPCR) methods have become widely used over recent years in the context of basic research and are now increasingly used in the field of medical diagnostics. However, the use of quantitative PCR in clinical fields (clinical microbiology, virology or oncology) requires accurate controls in order to be routinely used in clinical samples, particularly for low level mRNA targets. Over the last few years, the absence of standardized kits for commercially available attractive targets has led to the development of numerous in-house PCR assays. A review of the literature shows that the reported performances, both for the sensitivity and specificity of these assays, are often divergent.

An analysis of PCR techniques shows that falsepositive results due to carry-over and false-negative results due to PCR inhibition are not systematically controlled. These shortcomings of 'classical' PCR should be resolved with the development of standardized realtime PCR assays. Inter-laboratory comparisons should then be possible and regular quality controls will be necessary to ensure the reliability of real-time PCR assays.

Inter-laboratory quality assurance programs for diagnostic tests based on nucleic acid amplification are not widely implemented in clinical laboratories and remain limited to a few tests, mainly in hematology, microbiology and virology. The development of specific inter-laboratory quality assurance trials based on methodologic proficiency testing and directed to the evaluation of any diagnostic molecular target may be useful, particularly in breast cancer patients treated by hormone therapy. Endocrine manipulations are the most effective and least toxic form of systemic therapy currently available for the management of hormone-dependent breast cancer. The panel of available compounds has grown considerably over recent years, with the addition to the older agents, tamoxifen and high-dose progestogens, of type I and II aromatase inhibitors, pure anti-estrogens and, for premenopausal women, luteinizing hormonereleasing hormone analogs. The question of the determinants of resistance or sensitivity to treatment therefore needs to be considered. The estrogen receptor (ER) assay was first proposed by Jensen et al. (1971) to determine which patients are likely to respond to endocrine therapy. It was subsequently established that patients with ER-rich tumors respond to endocrine therapy, whereas patients with ER-negative tumors are unlikely to respond (McGuire et al. 1975). Although response rates of up to $70 \%$ are achieved with endocrine therapy in patients with tumors expressing ER and progesterone receptor (PR), most responsive tumors eventually acquire resistance. The mechanisms responsible for the resistance of tumors expressing ER and/or PR may be multifactorial. Molecular biotechnology offers a great potential for developing multiparametric analysis of mRNA expression of clinically relevant biological parameters in estrogen-dependent breast tumors.

We first evaluated endogenous controls for gene expression studies in breast cancer (F Spyratos, unpublished observations). The present study was designed to evaluate the accuracy of quantitative analyses of endocrine-related gene expression in breast cancer using realtime RT-PCR so that they can be used in prospective multicenter clinical trials. Quantitative RT-PCR assays may be particularly useful for quantitative determination of weakly expressed targets such as CYP19 (aromatase) and ER $\beta$ mRNA for which no consensus immunohistochemistry assay is available.

This quality control was performed between two independent laboratories (Centre René Huguenin (CRH) and Institut Curie (IC)) on a series of 79 breast cancer samples. The endocrine-related target genes were in-house assays designed by each laboratory (ER $\alpha, E R \beta, P R$ and CYP19). Similar Ki 67 and references gene (human acidic ribosomal phosphoprotein PO (RPLPO) and TATA boxbinding protein (TBP)) designs were used in both centers.

\section{Materials and methods}

\section{Human breast tumor samples}

A panel of 79 untreated residual breast tissue samples from informed patients undergoing primary surgery for breast cancer were retrospectively analyzed: 39 were provided by the $\mathrm{CRH}$ and 40 were provided by the IC. Tumor sampling was performed extemporaneously by a pathologist. Samples were frozen in liquid nitrogen within 20 min after resection using the same procedure in each center. The residual fragment was stored in liquid nitrogen in RNase-free conditions until use. We retrospectively analyzed this residual tissue for $\mathrm{ER} \alpha, \mathrm{ER} \beta, \mathrm{PR}$, CYP19 and Ki 67 mRNA expression. Adjacent fragments of frozen material were fixed in alcohol-formalin-acetic acid (AFA) and stained with hematoxylin and eosin in order to determine the proportion of tumor cells in each sample. Clinical staging and histological diagnosis were routinely determined in each case.

\section{Calibration curves}

Calibration curves were determined for each target gene using a unique mix of relevant total RNA including: a pool of total RNA from breast tumors known to have high levels of ER $\alpha$ transcripts and proteins, a pool of total RNA from breast tumors known to have high levels of PR transcripts and proteins (Bieche et al. 2001, de Cremoux et al. 2002), 
an ovarian total RNA, known to express high levels of ER $\beta$ transcripts (Moore et al. 1998, Pujol et al. 1998) (human ovary total RNA reference 735260 (Stratagene, Amsterdam, The Netherlands)) and a placental total RNA (Moore et al. 1998) (human placenta total RNA reference 64024-1 (Clontech, USA)) known to express high levels of CYP19 gene transcripts. Six-fold diluted cDNA (1:25 to $1: 800$ for ER $\beta, P R, K i$, TBP and RPLPO; 1:25 to $1: 3200$ for $E R \alpha$ and CYP19) were obtained after reverse transcription of the mix of these relevant total RNA and were amplified to obtain a standard curve and to assess PCR efficiency. The highest level of this calibration curve was used as calibrator in each experiment for each target gene.

\section{RNA extraction}

Total RNA was extracted from crushed tumor samples by the RNA plus kit (Bioprobe, Saint Quentin, France) at IC and by RNABle (Eurobio, Les Ulis, France) at CRH, according to the manufacturer's instructions. The RNA samples were stored in RNase-free distilled water, at $-80^{\circ} \mathrm{C}$. The quality of RNA samples was determined by electrophoresis on $2 \%$ agarose gel with ethidium bromide staining. The $18 \mathrm{~S}$ and $28 \mathrm{~S}$ RNA bands were visualized under u.v. light. All samples presented a high quality RNA profile. The quantity of RNA was measured by spectrophotometry at $260 \mathrm{~nm}$.

\section{cDNA synthesis}

RNA was reverse transcribed in one center $(\mathrm{CRH})$ to avoid possible differences related to variable efficiency of reverse transcriptases. Total RNA was reverse transcribed in a final volume of $20 \mu \mathrm{l}$ containing $1 \times$ reverse transcriptase buffer $(500 \mathrm{mM}$ of each deoxynucleotide triphosphate, $3 \mathrm{mM} \mathrm{MgCl} 2,75 \mathrm{mM} \mathrm{KCl}$ and $50 \mathrm{mM}$ Tris- $\mathrm{HCl}(\mathrm{pH} 8.3)$ ), 10 units RNase inhibitor (Promega, Madison, WI, USA), $10 \mathrm{mM}$ dithiothreitol, 50 units Superscript II RNase Hreverse transcriptase (Invitrogen), $1.5 \mathrm{mM}$ random hexamers (Pharmacia, Uppsala, Sweden) and $1 \mu \mathrm{g}$ total RNA (patient samples and calibrator). Samples were incubated at $20^{\circ} \mathrm{C}$ for $10 \mathrm{~min}$ and $42^{\circ} \mathrm{C}$ for $30 \mathrm{~min}$, reverse transcriptase was then inactivated by heating at $99^{\circ} \mathrm{C}$ for $5 \mathrm{~min}$ and cooling for $5 \mathrm{~min}$.

\section{Real-time PCR amplification}

$\mathrm{ER} \alpha, \mathrm{ER} \beta, \mathrm{PR}, \mathrm{CYP} 19$ and $\mathrm{Ki} 67$ transcripts were quantified using real-time quantitative RT-PCR assays. Primers and probes were selected by Oligo 4.0 (National Biosciences, Plymouth, MN, USA) (CRH) or Primer Express (Applied Biosystems, Foster City, CA, USA) (IC) software. The nucleotide sequences were then blasted against dbEST, htgs and nr (the non-redundant set of the GenBank, European Molecular Biology Laboratory (EMBL) and DNA Data Bank of Japan (DDBJ) database sequences) to confirm the total gene specificity of the nucleotide sequences chosen as primers and probes. To avoid amplification of contaminating genomic DNA, one of the two primers was placed in a different exon.

Each laboratory used its own design for $\mathrm{ER} \alpha, \mathrm{ER} \beta$, PR and CYP19 (Bieche et al. 2001, de Cremoux et al. 2002) gene transcript analysis. Common primers and probes designed by $\mathrm{CRH}$ were used for $\mathrm{Ki}$ 67, TBP and RPLPO (Bieche et al. 2000, Spyratos et al. 2002). The nucleotide and probe sequences are shown in Table 1.

PCR reactions were performed using an ABI Prism 7700 Sequence Detection System (Applied Biosystems) at IC. Real-time detection was performed under the usual conditions for each center: at $\mathrm{CRH}$, they were performed using the SYBR Green Core Reagent kit or the Taqman PCR Core Reagent kit (Applied Biosystems) and at IC they were performed using qPCR Core Reagent Kit (Eurogentec, Senaing, Belgium). Fluorescent probes were synthesized by Applied Biosystems, and primers were synthesized by Invitrogen (Paisley, Strathclyde, UK). The thermal cycling conditions comprised an initial denaturation step at $95^{\circ} \mathrm{C}$ for $10 \mathrm{~min}$, then 40 cycles at $95^{\circ} \mathrm{C}$ for $15 \mathrm{~s}$ and $1 \mathrm{~min}$ at an annealing temperature depending upon the target, as shown in Table 1. Transcripts of TBP (Spyratos et al. 2002) and RPLPO (Bieche et al. 2000, Spyratos et al. 2002) were quantified as endogenous RNA of reference genes to normalize the expression of the genes of interest. They were chosen according to a quality control study assessing the most adapted reference genes in breast tumor assays ( $F$ Spyratos, unpublished observations).

All measurements were performed in duplicate under blind conditions. Two non-template controls were included in each amplification run.

Results are expressed as $n$-fold differences in target gene expression relative to reference gene (either TBP and RPLPO) and the calibrator was defined as the ' $N$ target'. It was determined as follows: Ntarget $=1+$ $\left[\mathrm{E}_{\text {target }}^{\text {(Ctcalibrator-Ctsample) }} / \mathrm{E}_{\text {referencegene }}^{\text {(Ctcalibrator-Ctsample })}\right]$, where $\mathrm{E}$ is the efficiency of PCR measured using the slope of the calibration curve and $\mathrm{Ct}$ is the cycle threshold.

\section{Statistical analysis}

Data are expressed as ratios between the quantity of target transcripts and the quantity of the reference genes TBP and RPLPO, in arbitrary units. Non-parametric tests were used. Spearman's rank correlation was used to evaluate the relationship between relative mRNA expression of target genes at IC and $\mathrm{CRH}$, relative to both reference genes. 
de Cremoux et al.: Reliability of RT-PCR

Table 1 Primers and probe sequences for RT-PCR amplification

\begin{tabular}{|c|c|c|c|c|}
\hline Gene & $\begin{array}{l}\text { Annealing } \\
{ }^{\circ} \mathrm{C}\end{array}$ & $\begin{array}{l}\text { Product size } \\
\text { (nt) }\end{array}$ & Primers & Probe \\
\hline $\mathrm{ER} \alpha^{*}$ & 57 & 155 & $\begin{array}{l}\text { agcacccagtgaagctact } \\
\text { tgaggcacacaaactcct }\end{array}$ & tggctacatcatctctcggttccgca \\
\hline$E R \beta^{*}$ & 65 & 143 & $\begin{array}{l}\text { aagaatatctctgtgtcaaggccatg } \\
\text { ggcaatcacccaaaccaaag }\end{array}$ & ttgctgaacgccgtgaccgatg \\
\hline $\mathrm{PR}^{*}$ & 60 & 122 & $\begin{array}{l}\text { gaaccagatgtgatctatgcagga } \\
\text { cgaaaacctggcaatgatttagac }\end{array}$ & acctgacacctccagttctttgctgacaag \\
\hline CYP19* & 65 & 73 & $\begin{array}{l}\text { tggaaaacaactcgacccttct } \\
\text { cacagactgtgaccatacgaacaa }\end{array}$ & tgaaagctctgtcaggccccgg \\
\hline $\mathrm{ER} \alpha^{\dagger}$ & 65 & 108 & $\begin{array}{l}\text { ccaccaaccagtgcaccatt } \\
\text { ggtcttttcgtatcccacctttc }\end{array}$ & \\
\hline $\mathrm{ER} \beta^{\dagger}$ & 65 & 143 & $\begin{array}{l}\text { agagtccctggtgtgaagcaag } \\
\text { gacagcgcagaagtgagcatc }\end{array}$ & \\
\hline $\mathrm{PR}^{\dagger}$ & 65 & 121 & $\begin{array}{l}\text { cgcgctctaccctgcactc } \\
\text { tgaatccggcctcaggtagtt }\end{array}$ & \\
\hline CYP19 & 65 & 93 & $\begin{array}{l}\text { tgtggacgtgttgacccttct } \\
\text { accacgatagcactttcgtcca }\end{array}$ & atgctggacacctctaacacgctcttcttga \\
\hline Ki $67^{\dagger}$ & 65 & 105 & $\begin{array}{l}\text { attgaacctgcggaagagctga } \\
\text { ggagcgcagggatattccctta }\end{array}$ & acgacatgaaaaccaacaaaga \\
\hline $\mathrm{TPB}^{\dagger}$ & 65 & 89 & $\begin{array}{l}\text { cacgaaccacggcactgatt } \\
\text { tttcttgctgccagtctggac }\end{array}$ & tgtgcacaggagccaagagtgaaga \\
\hline RPLPO $^{\dagger}$ & 65 & 149 & $\begin{array}{l}\text { ggcgacctggaagtccaact } \\
\text { ccatcagcaccacagccttc }\end{array}$ & atctgctgcatctgcttggagccca \\
\hline
\end{tabular}

Primers and probes are designed by ${ }^{*} \mathrm{IC}$ and ${ }^{\dagger} \mathrm{CRH}$.

\section{Results}

The clinical and pathological characteristics of the tumors are shown in Table 2. The ER $\alpha$ and PR protein content were initially measured by enzyme immunoassay or immunohistochemistry (IHC). The distribution of ER/PR content was as follows: 43 (54\%) samples were ER positive and PR positive, 14 (18\%) samples were ER negative and PR negative, 17 (22\%) samples were ER positive and PR negative and five $(6 \%)$ samples were ER negative and PR positive.

\section{PCR optimization}

PCR optimization had been performed previously in each laboratory using similar rules as described (Bieche et al. 2001, Spyratos et al. 2002, de Cremoux et al. 2003).

The specificity of all PCR products was also initially determined in both centers by the presence of a single band of the expected size after migration on agarose gels.

The linearity for each target gene and reference gene was observed for more than $5 \log$ dilutions, including the observed samples values.

A calibration curve was generated by analyzing serial dilutions of the pool of RNA, as described in Materials and methods for each target and reference gene, to assess PCR efficiency. The PCR efficiency for $\mathrm{ER} \alpha, \mathrm{ER} \beta, \mathrm{PR}$, CYP19, Ki 67, RPLPO and TBP was above $90 \%$ for all genes. The intra-assay coefficient of variation $(\mathrm{CV})$ of $\mathrm{Ct}$ values was $<2 \%$ and the interassay $\mathrm{CV}$ was $<5 \%$ as calculated by the standard error.

\section{Correlation of target gene mRNA transcript levels between the two centers for each reference gene}

All results are expressed as continuous variables. For each parameter, and for both reference genes, the mean and standard deviation are presented in Table 3 for TBP and for RPLPO as reference genes. The levels of expression were comparable for all target genes in both centers. As shown in Tables 4 and 5, a statistically significant correlation $(P<0.0001)$ was demonstrated between the level of gene expression between the two centers for all target genes, considering either TBP or RPLPO as the reference gene.

\section{Correlation between target gene mRNA transcript levels}

We observed a positive correlation between ER $\alpha$ and PR transcript levels in both centers and with both reference genes, with correlation coefficients of 0.49 and 0.47 at IC, and 0.41 and 0.42 at CRH, using TBP and RPLPO $(P<0.001)$ respectively. No correlation was observed in this limited series between $\mathrm{ER} \alpha$ and $\mathrm{Ki} 67$ and aromatase transcripts. A weak inverse correlation was observed 
Table 2 Clinical and pathological characteristics of the samples

\begin{tabular}{lc}
\hline Characteristics & Number (\%) \\
\hline Patients and clinical & \\
tumor characteristics & \\
Age & \\
$\quad<50$ years & $16(20)$ \\
$\geq 50$ years & $63(80)$ \\
Tumour size & $17(21)$ \\
T1 & $48(61)$ \\
T2 & $14(18)$ \\
T3/T4 & \\
Nodal status & $55(70)$ \\
N0 & $22(28)$ \\
N1 & 1 \\
N2 & 1 \\
Unknown & \\
Histological characteristics & \\
Macroscopic tumor size & \\
$\quad<30$ mm & $48(61)$ \\
$\geq 30$ mm & $31(39)$ \\
Pathological nodal status & \\
pN ${ }^{-}$ & $36(46)$ \\
pN ${ }^{+}$ & $41(52)$ \\
No axillary dissection & 2 \\
Histological type & \\
Infiltrating ductal & $64(81)$ \\
Infiltrating lobular & $9(11)$ \\
Others & $6(8)$ \\
Grade (SBR) & \\
I & \\
II & \\
III & \\
Unknown & \\
Hormone receptor status & \\
ER Positive & \\
ER negative & \\
PR positive & \\
PR negative & $(25)$ \\
\hline
\end{tabular}

*Scarf, Bloom and Richardson

between ER $\alpha$ and ER $\beta$ only with TBP as reference gene at IC $(r=-0.33)$ and CRH $(r=-0.40)(P<0.003$ and $P<0.0004$ respectively).

\section{Interpretation of discrepancies}

The expression of all target genes was concordant for all samples but one: for example, samples expressing high levels of ER $\alpha$ and PR transcripts in one center expressed high levels of ER $\alpha$ and PR mRNA transcripts in the other center, except in one case where a $5 \mathrm{Ct}$ difference was observed between the ER $\alpha$ measurement performed at $\mathrm{CRH}$ and IC. This sample clearly expressed low levels of $\mathrm{ER} \alpha \mathrm{mRNA}$ at IC and high levels of ER $\alpha$ mRNA at $\mathrm{CRH}$, using both TBP and RPLPO as reference gene. Sequencing of the two ER $\alpha$ amplicons demonstrated that this sample presented a rare polymorphism in $1559 \mathrm{nt}$ ( $g t g>g g g$ ) in position 10 of the IC upper primer.

In conclusion, no other major discrepancy was observed in any of the target or reference genes.

\section{Discussion}

This study was designed to develop the first interlaboratory quality control to assess the accuracy and conditions of real-time RT-PCR assays for use in prospective clinical protocols in primary breast cancer.

For mRNA detection, we used a quantitative RTPCR method based on real-time analysis of PCR amplification. This assay is sensitive and allows accurate quantification of mRNA expression, as previously demonstrated for $\mathrm{ER} \alpha$ and $\mathrm{PR}$ transcripts by both laboratories (CRH and IC) (Bieche et al. 2001, de Cremoux et al. 2002, 2003, Spyratos et al. 2002). The real-time PCR method has several advantages over classical RT-PCR-based methods. It does not require post-PCR sample handling, thereby avoiding problems related to carry-over. It also has a wide dynamic range with very low intra-assay and interassay $\mathrm{CV}$ values $(<5 \%)$.

Real-time RT-PCR specific errors in the quantification of mRNA transcripts are usually correlated to possible variations in starting material which may be a major problem for patient samples for which sampling is uncertain (Freeman et al. 1999). To compensate for

Table 3 Expression level of target gene transcripts in both centers, using TBP and RPLPO as reference genes. Genes transcripts are expressed as means \pm S.D.

\begin{tabular}{|c|c|c|c|c|}
\hline \multirow{2}{*}{ Target gene } & \multicolumn{2}{|c|}{ TBP } & \multicolumn{2}{|c|}{ RPLPO } \\
\hline & IC & CRH & IC & CRH \\
\hline $\mathrm{ER} \alpha$ & $572 \pm 533$ & $482 \pm 454$ & $565 \pm 618$ & $606 \pm 997$ \\
\hline $\mathrm{ER} \beta$ & $39 \pm 46$ & $47 \pm 55$ & $34 \pm 37$ & $53 \pm 58$ \\
\hline PR & $358 \pm 419$ & $511 \pm 709$ & $317 \pm 400$ & $581 \pm 915$ \\
\hline CYP19* & $5361 \pm 5568$ & $7678 \pm 7563$ & $5346 \pm 6801$ & $9894 \pm 11003$ \\
\hline Ki 67 & $2127 \pm 1877$ & $1453 \pm 1359$ & $2167 \pm 3332$ & $1658 \pm 2037$ \\
\hline
\end{tabular}

* $\times 1000$. 
Table 4 Correlation between target gene transcript levels between IC and $\mathrm{CRH}$, using TBP as reference gene

\begin{tabular}{llc}
\hline \multirow{2}{*}{ Target gene } & \multicolumn{2}{c}{ Correlation* $^{*}$} \\
\cline { 2 - 3 } & $r$ & $P$ \\
\hline ER $\alpha$ & 0.93 & $<0.0001$ \\
ER $\beta$ & 0.92 & $<0.0001$ \\
PR & 0.98 & $<0.0001$ \\
CYP19 & 0.90 & $<0.0001$ \\
Ki 67 & 0.97 & $<0.0001$ \\
\hline
\end{tabular}

*, evaluated by Spearman's rank test.

sample-to-sample variations of mRNA content, each target gene was normalized with endogenous reference genes (RPLPO, TBP). The RT step also largely contributes to the overall variation of quantitative RT-PCR (Bustin 2000, Ovstebo et al. 2003). However, in this study, we used a common cDNA sample to avoid variations due to this step. Consequently, only the PCR step was evaluated in this quality control.

To compensate for any possible inter-PCR variation between runs, the expression of each target gene was calibrated. In these assays, designed to be used in clinical trials, the standard curve for the calibrator was prepared as a mix of human breast tumor samples and two marketed ovarian and placental RNAs known to present high levels of ER $\beta$ and CYP19 mRNA. The mix was used in all experiments, allowing us to control the reliability of the method over time. A calibration curve was included in each experiment and analyzed under the same conditions as for unknown samples. PCR efficiency was also calculated from the calibration curve in each experiment and for each transcript. The possible variation from one run to the next was therefore taken into account (as described in Materials and Methods). The use of a calibration curve for quantitative gene expression studies is not widely applied, but has been previously described to be a useful tool (Ovstebo et al. 2003).

Real-time RT-PCR analyses of tumor mRNA in both centers revealed a good correlation for each target gene and each control gene. We used different $\operatorname{ER} \alpha, \operatorname{ER} \beta, P R$ and CYP19 specific primer sets and probes and, as expected, we did not observe any differences due to the localization of the amplicon analyzed, except in one case for $E R \alpha$, corresponding to the presence of a rare polymorphism. The real-time PCR procedure and the PCR kit used did not influence the quantification of mRNA. The amplification conditions of the PCR assay described here were previously optimized and validated by each center (Bieche et al. 2001, de Cremoux et al. 2002). This collaborative study showed a high reproducibility of the PCR assay between two independent centers when
Table 5 Correlation between target gene transcript levels between IC and $\mathrm{CRH}$, using RPLPO as reference gene

\begin{tabular}{|c|c|c|}
\hline \multirow{2}{*}{ Target gene } & \multicolumn{2}{|c|}{ Correlation* } \\
\hline & $r$ & $P$ \\
\hline $\mathrm{ER} \alpha$ & 0.97 & $<0.0001$ \\
\hline $\mathrm{ER} \beta$ & 0.95 & $<0.0001$ \\
\hline PR & 0.98 & $<0.0001$ \\
\hline CYP19 & 0.91 & $<0.0001$ \\
\hline Ki 67 & 0.92 & $<0.0001$ \\
\hline
\end{tabular}

*, evaluated by Spearman's rank test.

identical cDNA were analyzed regardless of the PCR kit and design used.

Furthermore, this good correlation was not only found for genes with high mRNA expression, such as $\mathrm{ER} \alpha, \mathrm{PR}, \mathrm{Ki} 67$, but also for genes with low mRNA expression, such as CYP19 gene transcripts and ER $\beta$. This represents an additional relevant tool for analysis of hormone-dependent gene expression assays in clinical samples, where no other routinely adapted tool is currently available.

Multicenter validation and standardization of PCR have been previously described for the detection of foodborne bacteria transferred from animal to food products, by semiquantitative PCR, using a unique primer design for five pathogens (Hoorfar \& Cook 2003, Malorny et al. 2003). The present study represents the first real-time PCR quality control in breast cancer.

In another field, a multicenter European prospective study of the candidate references genes for diagnosis and residual disease detection in leukemic patients by quantitative RT-PCR was recently published (Beillard et al. 2003). This study initially selected three reference genes from a total of 14 (Abelson, $\beta 2$ microglobulin and $\beta$ glucuronidase) and prospective and retrospective studies on more than 400 samples confirmed that these three genes had a stable mRNA expression. However, the authors of this study propose that only the Abelson gene should be used as a reference gene for quantitative RTPCR analysis of residual disease, as its expression is not significantly different between normal and leukemic samples at diagnosis, confirming the major importance of these quality control studies before using these tools in prospective clinical trials. The results obtained in this study on snap-frozen material allowed us to use our protocol in a recent multicenter prospective clinical trial of neoadjuvant endocrine therapy whose preliminary results were presented in the last San Antonio Breast Cancer Symposium (Tubiana-Hulin et al. 2003).

In conclusion, we have developed the first independent quality control of mRNA expression of estrogen- 
dependent target genes in breast carcinoma by quantitative RT-PCR. The good correlation between two independent centers using a different design of PCR analysis allows these assays to be used for prospective clinical trials.

\section{Acknowledgements}

This work was supported by a grant from the Groupement des Entreprises Françaises dans la lutte contre le Cancer (GEFLUC).

\section{References}

Beillard E, Pallisgaard N, van der Veiden V, Bi W, Dee R, van der Schoot E, Delabesse E, Macintyre E, Gottardi E, Saglio G, Watzinger F, Lion T, van Dongen J, Hockland P \& Gabert J 2003 Evaluation of candidate control genes for diagnosis and residual disease detection in leukemic patients using 'real time' quantitative reverse-transcriptase polymerase chain reaction (RQ-PCR): a Europe against cancer program. Leukemia 17 1-13.

Bieche I, Nogues C, Paradis V, Olivi M, Bedossa P, Lidereau R \& Vidaud M 2000 Quantitation of hTERT gene expression in sporadic breast tumors with a real-time reverse transcriptionpolymerase chain reaction assay. Clinical Cancer Research $\mathbf{6}$ 452-459.

Bieche I, Parfait BIL, Girault I, Vidaud M \& Lidereau R 2001 Quantification of estrogen receptor alpha and beta expression in sporadic breast cancer. Oncogene 20 8109-8115.

Bustin S 2000 Absolute quantification of mRNA using real-time reverse transcription polymerase chain reaction assays. Journal of Molecular Endocrinology 25 169-193.

de Cremoux P, Tran-Perennou C, Elie C, Boudou E, Barbaroux C, Poupon MF, De Rycke Y, Asselain B \& Magdelenat H 2002 Quantitation of estradiol receptors alpha and beta and progesterone receptors in human breast tumors by real-time reverse transcription-polymerase chain reaction. Correlation with protein assays. Biochemical Pharmacology 64 507-515.

de Cremoux P, Tran-Perennou C, Brockdorff B, Boudou E, Brunner N, Magdelenat H \& Lykkesfeldt A 2003 Validation of real-time RT-PCR for analysis of human breast cancer cell lines resistant or sensitive to treatment with antiestrogens. Endocrine-Related Cancer 10 409-418.

Freeman WM, Walker SJ \& Vrana KE 1999 Quantitative RTPCR: pitfalls and potential. BioTechniques 26 112-122, 124-125.

Hoorfar J \& Cook N 2003 Critical aspects of standardization of PCR. Methods in Molecular Biology 216 51-64.

Jensen EV, Block GE, Smith S, Kyser K \& DeSombre ER 1971 Estrogen receptors and breast cancer response to adrenalectomy. National Cancer Institute Monographs $\mathbf{3 4}$ $55-70$.

McGuire WL, Carbone PP, Sears ME \& Escher CG 1975 Estrogen Receptors in Human Breast Cancer. An Overview. Eds McGuire WL, Carbone PP \& Vollner EP. New York: Raven Press.

Malorny B, Hoorfar J, Bunge C \& Helmuth R 2003 Multicenter validation of the analytical accuracy of Salmonella PCR: towards an international standard. Applied Environmental Microbiology 69 290-296.

Moore J, McKee D, Slentz-Kesler K, Moore L, Jones S, Horne E, Su J, Kliewer S, Lehmann J \& Willson T 1998 Cloning and characterization of human estrogen receptor beta isoforms. Biochemical and Biophysical Research Communications 247 75-78.

Ovstebo R, Haug K, Lande K \& Kierulf P 2003 PCR-based calibration curves for studies of quantitative gene expression in human monocytes: development and evaluation. Clinical Chemistry 49 425-432.

Pujol P, Rey J, Nirde P, Roger P, Gastaldi M, Laffargue F, Rochefort H \& Maudelonde T 1998 Differential expression of estrogen receptor-alpha and -beta messenger RNAs as a potential marker of ovarian carcinogenesis. Cancer Research 58 5367-5373.

Spyratos F, Bouchet C, Tozlu S, Labroquere M, Vignaud S, Becette V, Lidereau R \& Bieche I 2002 Prognostic value of uPA, PAI-1 and PAI-2 mRNA expression in primary breast cancer. Anticancer Research 22 2997-3003.

Tubiana-Hulin M, Spyratos F, Becette V, Mauriac L, Romieu G, Bibeau F, Bieche I, Bourgeois H \& Chollet P 2003 Phase II study of neo-adjuvant exemestane in postmenopausal patients with operable breast cancer (26th Annual San Antonio Breast Cancer Symposium, December 3-6). Breast Cancer Research Treatment 82 (Suppl 1) A443. 